\title{
Computed tomography-guided endoscopic sinusotomy for an ileal pouch presacral sinus
}

Endoscopic sinusotomy for ileal pouch sinus, a detrimental complication caused by chronic anastomotic leak, is an effective and safe treatment option [1]. Endoscopic sinusotomy requires access to the sinus from the pouch lumen and has been considered infeasible in patients with a sealed sinus. We describe herein the first endoscopic sinusotomy for a sealed sinus using computed tomography (CT)-guided wire placement.

The patient was a 28-year-old man diagnosed with ulcerative colitis in 2002, who underwent restorative proctocolectomy with an ileal pouch-anal anastomosis (IPAA). He was later diagnosed with Crohn's disease based on the presence of inflammation in the pouch body and afferent limb and was started on adalimumab. He was referred for the management of a $2.7 \times 1.6-\mathrm{cm}$ presacral sinus that had been found on magnetic resonance imaging (MRI) in 2017 ( $>$ Fig. 1 a). He had symptoms of failure to thrive, tailbone pain, and night sweats.

Pouchoscopy was performed which failed to detect a sinus opening. We then decided to use CT-guided wire placement to gain access to the sinus through the side of the pouch. An experienced radiologist advanced a 17-Fr trocar needle cutaneously, through the collection and into the pouch, and this was followed by wire

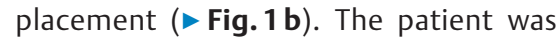
subsequently brought to the endoscopy suite, where he received conscious sedation. After the area had been tattooed, partial endoscopic sinusotomy was performed along the path of the wire using

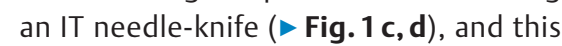
was followed by placement of five endoclips to maintain the patency of the orifice ( $\triangleright$ Video 1 ).

Complete endoscopic sinusotomy was performed 1 month later, followed by placement of endoclips to maintain pa-
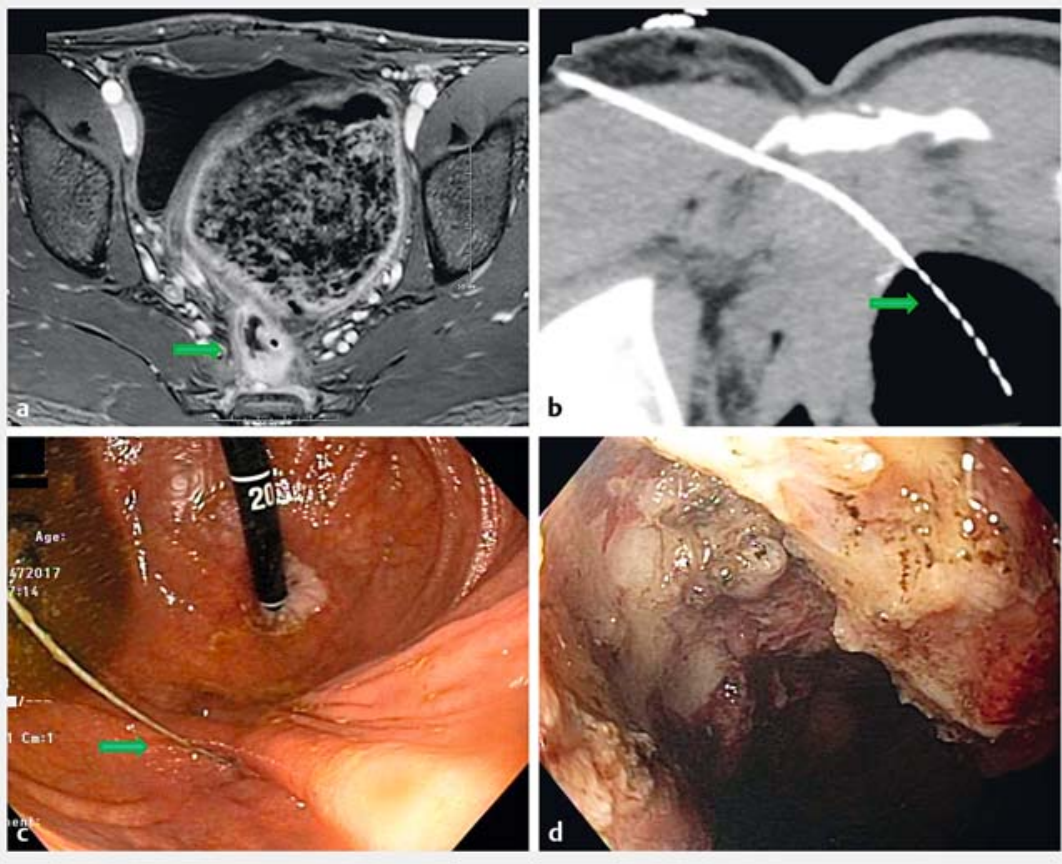

- Fig. 1 The endoscopic sinusotomy procedure. a Contrast-enhanced T1 weighted axial magnetic resonance image through the lower pelvis showing a peripherally enhancing presacral collection without an identified communicating sinus to the adjacent ileal pouch. b Sagittal reconstruction computed tomography image partially showing the guidewire placed into the presacral collection. $\mathbf{c}$ Retroflexed endoscopic view showing the guidewire locating the presacral sinus. $\mathbf{d}$ Endoscopic view following the successful needle-knife sinusotomy.

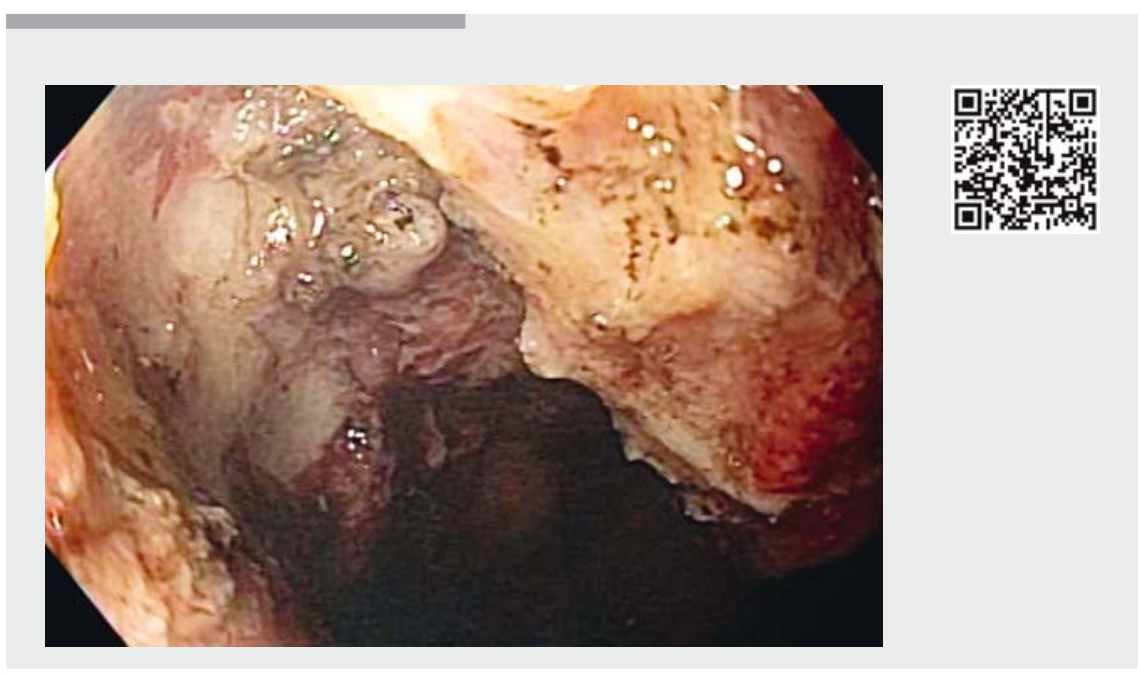

$\nabla$ Video 1 Video demonstrating computed tomography-guided needle-knife sinusotomy. 
tency. The patient tolerated the procedures well, with resolution of his symptoms.

Endoscopy_UCTN_Code_TTT_1AQ_2AG

\section{Competing interests}

None

The authors

Sara El Ouali, Joseph C. Veniero, Bo Shen

1 Digestive Disease Institute, Cleveland Clinic Abu Dhabi, Abu Dhabi, UAE

2 Imaging Institute, Cleveland Clinic, Cleveland, Ohio, USA

3 Interventional Inflammatory Bowel Disease (i-IBD) Unit, Digestive Disease and Surgery Institute, The Cleveland Clinic Foundation, Cleveland, Ohio, USA
Corresponding author

\section{Sara El Ouali, MD}

Cleveland Clinic Abu Dhabi, Al Maryah Island, PO Box 112412, Abu Dhabi, UAE

Elouals@clevelandclinicabudhabi.ae

\section{Reference}

[1] Wu XR, Wong RC, Shen B. Endoscopic needle-knife therapy for ileal pouch sinus: a novel approach for the surgical adverse event (with video). Gastrointest Endosc 2013; 78: 875-885

\section{Bibliography}

DOI https://doi.org/10.1055/a-0596-7107

Published online: 9.5.2018

Endoscopy 2018; 50: 730-731

(c) Georg Thieme Verlag KG

Stuttgart · New York

ISSN 0013-726X
ENDOSCOPY E-VIDEOS

https:/|eref.thieme.de/e-videos

回直 Endoscopy E-Videos is a free access online section, reporting 回: on interesting cases and new techniques in gastroenterological endoscopy. All papers include a high quality video and all contributions are freely accessible online.

This section has its own submission website at

https://mc.manuscriptcentral.com/e-videos 